\title{
Corrosion Rate of the X2CrNiMoN22-5-3 Duplex Stainless Steel Annealed at $500^{\circ} \mathrm{C}$
}

\author{
T. LIPIŃSKI* \\ University of Warmia and Mazury in Olsztyn, Faculty of Technical Sciences, \\ St. Oczapowskiego 11, 10-957 Olsztyn, Poland
}

\begin{abstract}
The X2CrNiMoN22-5-3 duplex stainless steel has an austenitic-ferritic microstructure with an average fraction of each phase of approximately $50 \%$. At the duplex stainless steel the nitrogen serves to significantly improve the corrosion resistance of the alloy also in the welded condition. These steels present the excellent corrosion resistance of austenite steel, and the high mechanical behaviour of ferrite steel. However, the performance presented by duplex stainless steels can be drastically reduced by undesirable phases, such as sigma phase, chi phase, secondary austenite and a lot of chromium-rich and carbides precipitates. In this case an upper temperature limit of $300^{\circ} \mathrm{C}$ has been placed in the use of X2CrNiMoN22-5-3 steel in the industry mainly due to $475{ }^{\circ} \mathrm{C}$ embrittlement. The purpose of this work was to ascertain how 60 min isothermal heat treatments at $500^{\circ} \mathrm{C}$ and corrosion time influence on the relative mass loss, profile roughness parameters and endothermal process by dynamic scanning calorimetry curves of heating measurement from 400 to $600{ }^{\circ} \mathrm{C}$ of X2CrNiMoN22-5-3 duplex stainless steel. The influence of boiling nitric acid on the steel corrosion resistance was investigated using weight loss and profile roughness parameters.
\end{abstract}

DOI: 10.12693/APhysPolA.130.993

PACS/topics: $81.40 .-\mathrm{Z}$

\section{Introduction}

Duplex stainless steels are interest of various industrial applications as a construction material. Main grades of these steels are ferritic, austenitic and martensitic steels microstructure. High chromium and molybdenum contents provide excellent resistance to pitting and crevice corrosion [1-5]. They are used in a wide range of industrial applications, but their properties are continuously studied to improve the quality of properties [6-9]. But the microstructure as well as percentage of each phase and utilities properties of steels are determined by phase transformation during its thermal processing, technological processes, heat treatments, and critical cooling rate [10-15]. The formation of intermetallic phases such as sigma phase occurs in the temperature range $600-950^{\circ} \mathrm{C}$ and reformation of ferrite occurs in the range $350-525^{\circ} \mathrm{C}\left(475^{\circ} \mathrm{C}\right.$ embrittlement $)$. However, the performance presented by super duplex stainless steels can be drastically reduced by undesirable phases, such as sigma phase, chi phase, secondary austenite and a lot of chromium-rich and carbides precipitates. Sigma phase is rich in chromium and molybdenum is formed by ferrite decomposition, in the temperature over $500^{\circ} \mathrm{C}$. In normal alloying, heat-treatment or welding processes the risk of embrittlement is not too high. However risks exist for example in the failure that can arise during its operation causing overheating, especially if the cooling is slow. Generally, with the higher the superheating temperature is the higher the ferrite content. The steel must be heated to a very high temperature to become

\footnotetext{
*e-mail: tomekl@uwm.edu.pl
}

completely ferritic. Then heat treatment process, for both solution annealing and stress relieving, is advisable at certain temperatures with subsequent rapid cooling in water $[12,15-18]$. The embrittlement and hardness were caused by the decomposition of the ferrite phase in a two-phase iron-chromium alloy to chromium-rich $\alpha^{\prime}$ phase and an iron-rich $\alpha$ phase in the temperature range of $280-500^{\circ} \mathrm{C}$. This temperature is very important to use steel because it is determines the maximum recommended operating temperature of steel.

The purpose of this work was to ascertain how $60 \mathrm{~min}$ isothermal heat treatments at $500^{\circ} \mathrm{C}$ and corrosion time effect the relative mass loss and profile roughness parameters of X2CrNiMoN22-5-3 duplex stainless steel.

\section{Materials and methods}

The experiments were performed with duplex stainless $\mathrm{X} 2 \mathrm{CrNiMoN22-5-3}$ steel. The chemical composition of the X2CrNiMoN22-5-3 steel is presented in Table I.

TABLE I

Chemical composition of the X2CrNiMoN22-5-3 steel [wt\%].

\begin{tabular}{c|c|c|c|c|c|c|c|c|c|c}
\hline \hline $\mathrm{C}$ & $\mathrm{Si}$ & $\mathrm{Mn}$ & $\mathrm{P}$ & $\mathrm{S}$ & $\mathrm{N}$ & $\mathrm{Cr}$ & $\mathrm{Mo}$ & $\mathrm{Ni}$ & $\mathrm{Cu}$ & $\mathrm{Fe}$ \\
\hline 0.022 & 0.35 & 1.40 & 0.019 & 0.001 & 0.18 & 22.24 & 2.48 & 5.25 & 0.145 & bal.
\end{tabular}

Before experiments, the specimens with an area of $13 \mathrm{~cm}^{2}\left(4 \times 1 \times 0.5 \mathrm{~cm}^{3}\right)$ were successively polished with 400 grades of emery paper, next mechanically cleaned with $95 \% \mathrm{C}_{2} \mathrm{H}_{5} \mathrm{OH}$ alcohol.

The samples were held at a temperature of $500{ }^{\circ} \mathrm{C}$ by 60 min and cooled down in air, accordance with standard PN EN ISO 3651-1 (Determination of resistance to intergranular corrosion of stainless steels. Part 1: Austenitic 
and ferritic-austenitic (duplex) stainless steels). Corrosion test in nitric acid medium was made by measurement of loss in mass (the Huey test); corrosive media were represented by boiling nitric acid $\mathrm{V} 65 \%$.

The samples of X2CrNiMoN22-5-3 steel (about $10 \mathrm{mg}$ ) were analyzed using dynamic scanning calorimetry (DSC) measurement by NEITSH DSC204 F1 Phoenix and DSC/dt in nitrogen atmosphere (with a constant flow of $20 \mathrm{ml} / \mathrm{min}$ ) using Neitsch-Proteus 5.1 software. DSC measurements were carried out in a temperature range $\left(20-61^{\circ} \mathrm{C}\right)$ with a heating rate of $10^{\circ} \mathrm{C} / \mathrm{min}$.

The corrosion rate of the $\mathrm{X} 2 \mathrm{CrNiMoN22-5-3}$ steel measured in $\mathrm{mm} /$ year was calculated with the use of the below formula (1):

$$
r_{\mathrm{cor}}=\frac{8760 m}{S t \rho}
$$

where $t$ - time of treatment in a corrosive solution of boiling nitric acid [h], $S$ - surface area of the sample $\left[\mathrm{cm}^{2}\right], m$ - average mass loss in boiling solution [g], $\rho$ - sample density $\left[\mathrm{g} / \mathrm{cm}^{3}\right]$.

The influence of boiling nitric acid on the $\mathrm{X} 2 \mathrm{CrNiMoN} 22-5-3$ steel corrosion resistance was investigated using weight loss. The mass of samples were measured by Kern ALT 3104AM general laboratory precision balance with accuracy of measurement $0.0001 \mathrm{~g}$.

Profile roughness parameters were analyzed according to the PN-EN 10049:2014-03 standard (Measurement of roughness average $\mathrm{Ra}$ and peak count $\mathrm{RPc}$ on metallic flat products) by the Diavite DH5 profilometer.

\section{Results}

Quantitative X-ray analysis of the X2CrNiMoN22-53 duplex stainless steel annealed at $500^{\circ} \mathrm{C}$ was confirmed by quantitative X-ray analysis (Fig. 1). The peaks corresponding to austenite and ferrites were identified. The steel had an almost 53:47 austenite:ferrite ratio which is very beneficial to the microstructure and corrosion rate. No evidence was observed for any other precipitates such as chi phase, nitrides, and carbides which might be correlated to the low volume fraction of these precipitates. Lattice parameter for austenite is 3.604 Aand for ferrite $2.878 \AA$. For (111) peak position are: $43.428^{\circ}$ for austenite and $44.451^{\circ}$ for ferrite, and its intensity respectively are 299 and 382 .

Dynamic scanning calorimetry curves of heating measurement from 400 to $600{ }^{\circ} \mathrm{C}$ (according to literature embrittlement temperature of $475^{\circ} \mathrm{C}$ ) the super duplex steel for heating rate $10^{\circ} \mathrm{C} / \mathrm{min}$, as an example is presented in Fig. 2.

The endothermic peak (Fig. 2) involving $9.106 \mathrm{~J} / \mathrm{g}$ of reaction enthalpy with a $T_{\text {onset }}$ at about $46^{\circ} \mathrm{C}, T_{\text {end }}$ at about $549^{\circ} \mathrm{C}$ and $T_{\text {peak }}$ about $519^{\circ} \mathrm{C}$ according to literature $[12,17,18]$ represents dissolving of chromium-rich $\alpha^{\prime}$-phase. The reformation of ferrite occurs in the range $350-525^{\circ} \mathrm{C}$ is determining as the $475^{\circ} \mathrm{C}$ embrittlement. For this sample $C_{p}$ is about $0.078 \mathrm{~J} /(\mathrm{g} \mathrm{K})$.

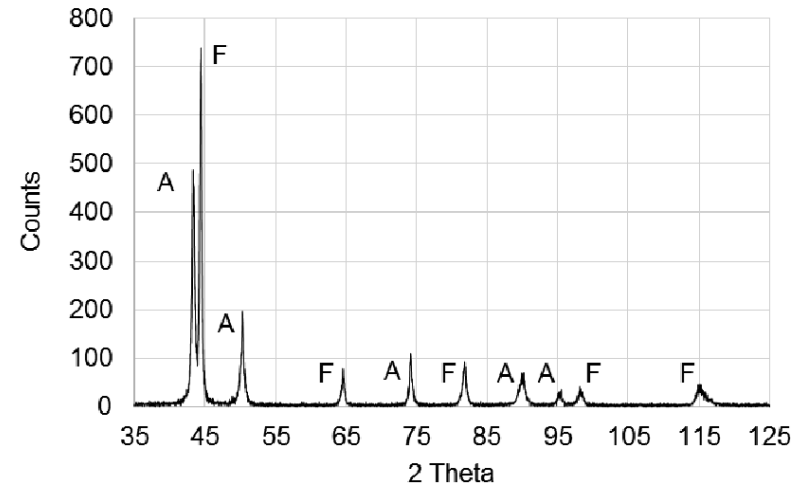

Fig. 1. Quantitative X-ray analysis of the X2CrNiMoN22-5-3 duplex stainless steel annealed at $500^{\circ} \mathrm{C}$.

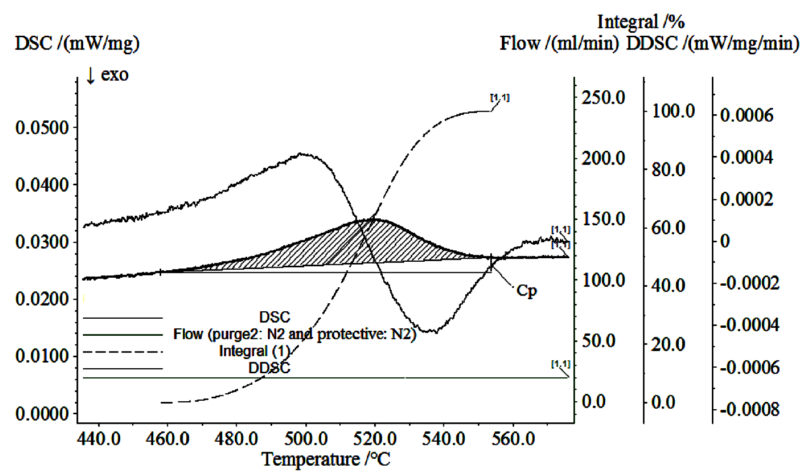

Fig. 2. DSC and DDSC curves of heating measurement the $\mathrm{X} 2 \mathrm{CrNiMoN} 22-5-3$ duplex stainless steel. Heating rate $10^{\circ} \mathrm{C} / \mathrm{min}$.

Profile roughness parameters of X2CrNiMoN22-5-3 steel with: $R_{a}$ - arithmetic average of absolute values $[\mu \mathrm{m}], R_{p}$ - maximum peak height $[\mu \mathrm{m}], R_{q}$ - root mean squared $[\mu \mathrm{m}], R_{t}$ - maximum height of the profile $[\mu \mathrm{m}]$ after corrosion tests in boiling $\mathrm{HNO}_{3}$ for different boiling time is presented in Fig. 3, regression equation and correlation coefficient $r$ at (2)-(5):

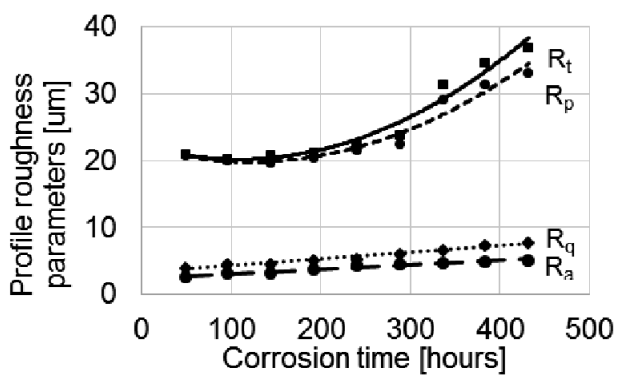

Fig. 3. Profile roughness parameters of X2CrNiMoN22-5-3 steel annealed at $500^{\circ} \mathrm{C}$ by $60 \mathrm{~min}$ and cooling down in air after corrosion tests in boiling $\mathrm{HNO}_{3}$. 


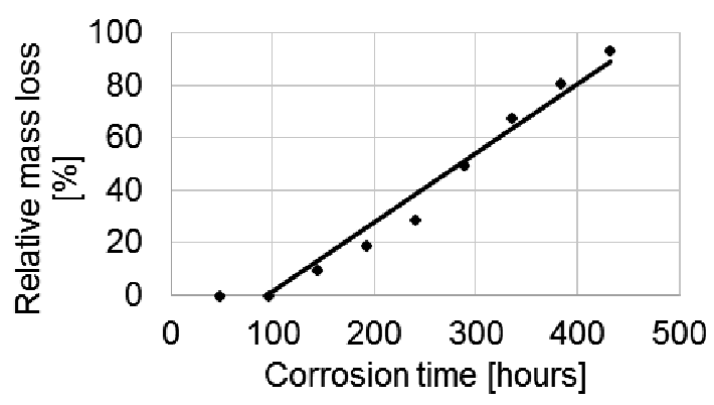

Fig. 4. Percentage effects of corrosion time on the relative mass loss (RML) of X2CrNiMoN22-5-3 steel annealed at $500{ }^{\circ} \mathrm{C}$ by $60 \mathrm{~min}$ and cooling down in air.

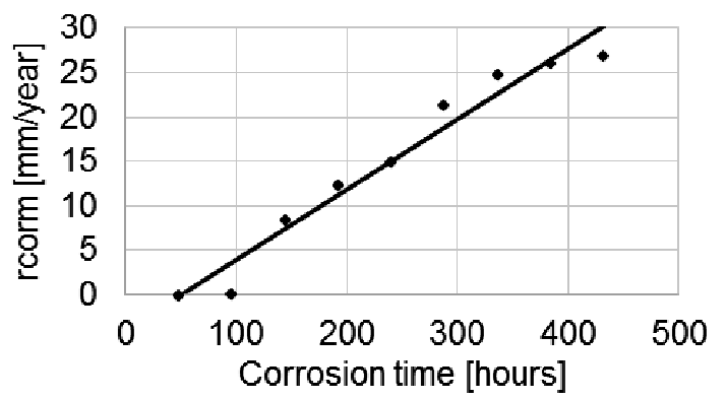

Fig. 5. Effects of corrosion time on the corrosion rate measured in $\mathrm{mm}$ per year of $\mathrm{X} 2 \mathrm{CrNiMoN} 22-5-3$ steel annealed at $500^{\circ} \mathrm{C}$ by $60 \mathrm{~min}$ and cooling down in air.

$$
\begin{aligned}
& R_{a}=0.0066 t+2.42 \text { and } r=0.9857, \\
& R_{q}=0.01 t+3.25 \text { and } r=0.9840, \\
& R_{p}=0.0002 t^{2}-0.037 t+22 \text { and } r=0.9769, \\
& R_{t}=0.0002 t^{2}-0.038 t+22.3 \text { and } r=0.9806 .
\end{aligned}
$$

Percentage effects of corrosion time on the relative mass loss (RML) of X2CrNiMoN22-5-3 steel annealed at $500{ }^{\circ} \mathrm{C}$ by $60 \mathrm{~min}$ and cooling down in air is presented in Fig. 4, regression equation and correlation coefficient $r$ at $(6)$ :

$$
\mathrm{RML}=0.261 t-24.6 \text { and } r=0.9825 \text {. }
$$

Effects of corrosion time on the corrosion rate measured in mm per year of X2CrNiMoN22-5-3 steel annealed at $500{ }^{\circ} \mathrm{C}$ by $60 \mathrm{~min}$ and cooling down in air is presented in Fig. 5, regression equation and correlation coefficient $r$ at $(7)$ :

$$
r_{\text {cor }}=0.079 t-3.98 \text { and } r=0.9789 \text {. }
$$

\section{Conclusions}

Based on the results obtained in this work the following conclusions could be drawn:

- Annealing the X2CrNiMoN22-5-3 duplex steels at started temperature $465^{\circ} \mathrm{C}$ to $549^{\circ} \mathrm{C}$ causes dissolving of chromium-rich $\alpha^{\prime}$-phase.
- The results of the tests indicate that the loss of weight of $\mathrm{X} 2 \mathrm{CrNiMoN22-5-3}$ steel annealed at $500{ }^{\circ} \mathrm{C}$ by $60 \mathrm{~min}$ and cooling down in air is proportional to time of corrosion.

- Profile roughness parameters such as $R_{\mathrm{a}}$ and $R_{\mathrm{q}}$ increase with time of the corrosion process while whereas $R_{t}$ and $R_{p}$ in the first stage of corrosion did not change, while in the second period increased exponentially.

- Based on profiles of roughness parameters can determine the size of duplex steel corrosion.

- The austenite:ferrite ratio annealed at $500{ }^{\circ} \mathrm{C}$ of $\mathrm{X} 2 \mathrm{CrNiMoN22-5-3}$ steel protects it against corrosion.

\section{References}

[1] A. Momeni, K. Dehghani, X.X. Zhang, J. Mater. Sci. 47, 2966 (2012).

[2] J. Nowacki, A. Łukojć, Mater. Character. 56, 436 (2006).

[3] P. Szabracki, T. Lipiński, in: Proc. 23rd Int. Conf. on Metallurgy and Materials, Metal 2014, TANGER Ltd., Ostrava 2014, p. 476.

[4] A. Dudek, A. Wrońska, L. Adamczyk, J. Solid State Electrochem. 18, 2973 (2014).

[5] P. Szabracki, T. Lipiński, Solid State Phenom. 203204, 59 (2013).

[6] S. Topolska, J.Łabanowski, J. Achiev. Mater. Manufact. Eng. 36, 142 (2009).

[7] J. Selejdak, R. Ulewicz, M. Ingaldi, as Ref. [3], p. 1882.

[8] D.S. Petrovic, M. Pirnat, G. Klancnik, P. Mrvar, J. Medved, J. Therm. Anal. Calorim. 109, 1185 (2012).

[9] J. Pietraszek, A. Gadek-Moszczak, Solid State Phenom. 197, 162 (2013).

[10] M. Scendo, N. Radek, J. Trela, Int. J. Electrochem. Sci. 8, 9264 (2013).

[11] R. Ulewicz, Metallurgija 42, 61 (2003).

[12] S. Shi, G. Ma, B. Guo, K. Fang, J. Wang, J. Mater. Eng. Perf. 23, 2043 (2014).

[13] W. Wołczyński, E. Guzik, W. Wajda, D. Jedrzejczyk, B. Kania, M. Kostrzewa, Archiv. Metall. Mater. 57, 105 (2012).

[14] W. Pilarczyk, Cryst. Res. Technol. 50, 700 (2015).

[15] R. Włodarczyk, A. Dudek, Z. Nitkiewicz, Archiv. Metall. Mater. 56, 181 (2011).

[16] K.L. Weng, H.R. Chen, J.R. Yang, Mater. Sci. Eng. A 379, 119 (2004).

[17] V. Freitas, P.G. Normando, V. Albuquerque, E. de Macedo Silva, A. Silva, J.R.S. Tavares, J. Nondestruct. Eval. 30, 130 (2011).

[18] S.S.M. Tavares, V.F. Terra, J. Mater. Sci. 40, 4025 (2005). 